\title{
Design and Analysis of Rotating Stator in Electrical Machine System
}

\author{
Jotham Jeremy Lourdes and Rosmiwati Mohd-Mokhtar* \\ School of Electrical and Electronic Engineering, Universiti Sains Malaysia, \\ Engineering Campus, 14300 Nibong Tebal, Pulau Pinang, Malaysia \\ "Corresponding author: eerosmiwati@usm.my
}

Published online: 30 April 2019

To cite this article: Jotham Jeremy Lourdes and Rosmiwati Mohd-Mokhtar (2019). Design and analysis of rotating stator in electrical machine system. Journal of Engineering Science, 15, 35-48, https://doi.org/10.21315/jes2019.15.4.

To link to this article: https://doi.org/10.21315/jes2019.15.4

\begin{abstract}
This paper presents a study on effect of rotating stator in electrical machine system. The designed generator is different from the conventional one, in which in conventional system, only rotor is rotating and the stator is fixed. In this study, both rotor and stator are allowed to rotate. The objective of this study is to investigate and analyse the potential improvement to the electrical power generation if the stator part is also allowed to rotate. The direct current (DC) machine is redesigned in such a way that both stator and rotor can be rotated. In this paper, a model of DC generator is observed for the following conditions; when only stator rotates, when only rotor rotates, when both rotor and stator rotate in opposite direction and when both rotor and stator rotate in same. From result, it is observed that the output voltage that is produced when both rotor and stator are rotating is higher than to normal rotor only rotated. This indicates the possibility of generating more electrical power using this configuration.
\end{abstract}

Keywords: DC generator, rotating stator, Faraday's law, rotor

\section{INTRODUCTION}

An electrical machine is a device that can convert either mechanical energy to electrical energy or vice versa. ${ }^{1}$ A generator is a device that converts mechanical energy to electrical energy, whereas a motor converts electrical energy to mechanical energy. An electrical machine can be used as both generator and motor since it can be converted in any direction depending on the power flow. Almost all machines use some sort of magnetic fields to perform actions. The energy that comes from the machine systems is clean and efficient; hence this is why they are commonly used as compared to other sources of energy. 
An electric machine works on five principal components: (1) field system, (2) armature coil, (3) armature winding, (4) commutator and (5) brushes. ${ }^{2,3,4}$ Figure 1 shows the cross section of two-pole direct current (DC) generator. According to Faraday's law of electromagnetic induction, it stated that if and whenever a conductor is placed or moved in a varying magnetic field, an electromotive force (EMF) is induced on conductor. The magnitude of induction can be calculated using the EMF equation. ${ }^{2,3,4}$

$$
E=-N \frac{\Delta \Phi_{B}}{\Delta t}
$$

where $N$ is number of turns of coil and $\Phi_{B}$ is the magnetic flux through a single loop.

The voltage induced will depend on three factors: ${ }^{2}(1)$ the flux in the machine, (2) the speed of rotation and (3) a constant which representing the construction of the machine. A commutation process whereby the loop connections on the rotor of a DC machine are switched just as the voltage in the loop switches polarity will assure the constant DC output voltage is maintained.

DC generators are DC machines used as generators. An electric generator consists of a magnet and a coil where the magnet or the coil moves to produce a change in flux over time. This produces a current to flow as change in the flux over time is proportional to the potential of the sub-circuit and a flow of current is required to generate a field. A DC generator has a stationary portion (the stator) and a rotating portion (the rotor) that rotates around the stator. The stator includes permanent magnets placed at an interval along a surface of the rotor. ${ }^{5}$ The rotor comprises of an inner support structure around which a plurality of magnets having windings are disposed in a circumferential fashion. An intermediate layer between the rotor and the stator is comprised of a bearing that allows movement of the rotor relative to the stator.

Most of the electric machines in industry have a fixed stator. Stator is the stationary part of an electrical machine system, found in electric generators, motors and so on. It is to keep the magnetic field aligned. Stator may also be inclusive of all other stationary part in the system. In this study, this is the part where it will be altered so that it can also rotate. In the other hand, rotor is the common rotating part in the electrical machine system. Generally, when higher electrical current is applied to the motor, the rotor spins faster. ${ }^{6}$ For a generator, when the rotor is spun quicker by any mean of source, the generator will generate more power. 


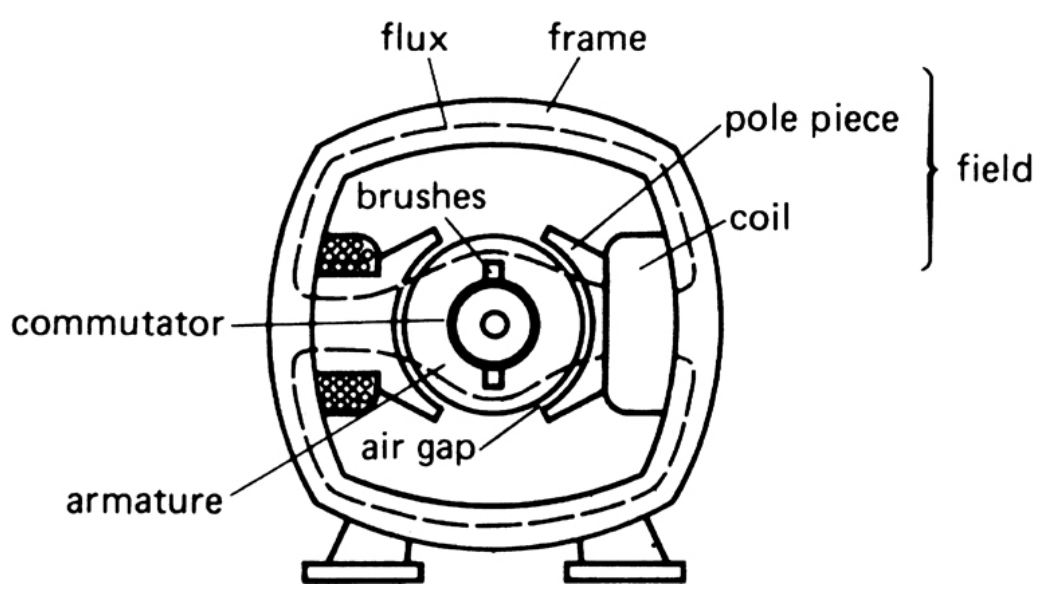

Figure 1: Cross section of two-pole DC generator. ${ }^{3}$

In this project, changes will be made in which a fixed stator will be made rotating and its effect on the power output will be examined. The aim of the study is to find out whether the power generation will be increased or will remain the same. If it is proven in which the outcome will be more, then this approach can be considered as an improvement to generating more power. The application of DC generator and motor in current era is limited therefore they are used for small and medium range alternators excitation. Due to the availability of rectifiers, alternative current (AC) is generated first and then it is converted to DC by the rectifiers. The use of DC generator depends on the way it is excited. In separately excited DC generator, they are used in laboratory experiments to supply source to DC motors. In shunt generator, it is used for lighting purpose and sometimes to charge batteries. In series generator, it is used for booster in distribution networks. ${ }^{7}$

From literature search, the study on designing an electric machine with rotating stator is not fully explored. There are only four patents found on this matter which mainly discussed on mechanical configuration of having the rotating stator for improvement of power generation. First patent was published in 2006 by Miller and Ata. ${ }^{8}$ The source of energy supply to give mechanical force is taken from the renewable source such as wind and water flow. Double blades in wind turbine, water turbines and also planetarium gear combinations are shown as an example to harvest more energy.

In patent published by Amutham, ${ }^{9}$ an in-wheel motor having an inner stationary (the stator) and the outer rotating part (the rotor) rotates around the stator and drives a wheel directly attached to the rotor. An inner stationary 
stator includes a plurality of magnets comprised on windings and an outer rotor surrounding the inner stator includes a plurality of rotor magnets which are arranged circumferentially. Although it is said as rotating stator, the actual part that is rotating is still a rotor, which was located in the outer part instead of inner for standard motor configuration.

Similar to patent by Miller and Ata, ${ }^{8}$ there were two other patents published in 2016. ${ }^{10,11}$ The concept of counter rotation between the stator and the rotor is the same, only with different improvement in terms of mechanical assembly of the system. In all the literature as mentioned, the mechanical design and configuration of the system were shown, however, the analysis as to whether the concept is proven in generating more power is yet not clear. Thus, this research is conducted with the aim to design a simple prototype of electric generator having both stator and rotor that can rotate and analysis is done as to verify the applicability of the system in improving the electric power generation. In this project the rotor, coil, shaft, collector and brushes are to be maintained as a constant whereas the stator is set to be variable.

Overall, this paper goes as follow. Section 2 will discuss on methodology on how the implementation goes on from normal only rotor rotates to the modified one which having the stator also rotates. The outcome from this study is shown in results and discussion section in Section 3. Finally, Section 4 concludes the paper.

\section{MATERIALS AND METHODS}

In order to achieve the objective of this project, two types of mini DC generators were developed. This project required several hardware components such as five DC motors, wires for connection, wood to hold the motor, aluminium foil and glue. The 1.5-3.0 V DC motor was used as shown in Figure 2. It is a brushed type DC motor. The electrical specification of the motor is tabulated in Table 1. 


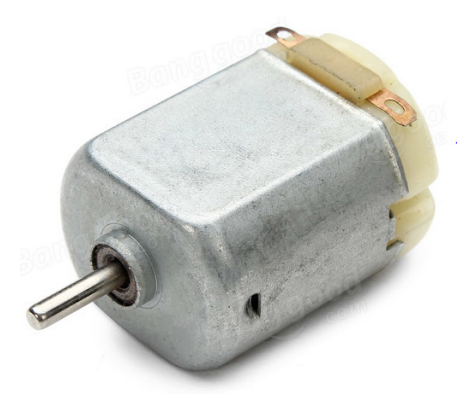

Figure 2: 1.5-3.0 V DC motor.

Table 1: Electrical specification.

\begin{tabular}{ll}
\hline Specifications & Value \\
\hline Supply voltage & $1.5-3.0 \mathrm{~V}$ \\
Speed at max. efficiency & $6,990 \mathrm{rpm} @ 1.5 \mathrm{~V}$ \\
Current at max. efficiency & $0.66 \mathrm{~A} @ 1.5 \mathrm{~V}$ \\
Output power at max. efficiency & $0.43 \mathrm{~W} @ 1.5 \mathrm{~V}$ \\
Torque & $6 \mathrm{gf.cm}(0.0006 \mathrm{Nm})$ \\
Shaft diameter & $2 \mathrm{~mm}$ \\
Weight & $17 \mathrm{~g}$ \\
Dimensions & $20.1 \times 16.5 \times 28.6 \mathrm{~mm}$ \\
& $(38 \mathrm{~mm}$ including shaft $)$ \\
\hline
\end{tabular}

The first design is the conventional generator that has a fixed stator. This generator is developed by using only two DC motors joined together as shown in Figure 3. The generator (right) is connected directly to the driving motor (left). In this case, the losses due to transfer of energy can be minimised. The purpose of developing this generator is to make it as reference to the second generator design later on. 


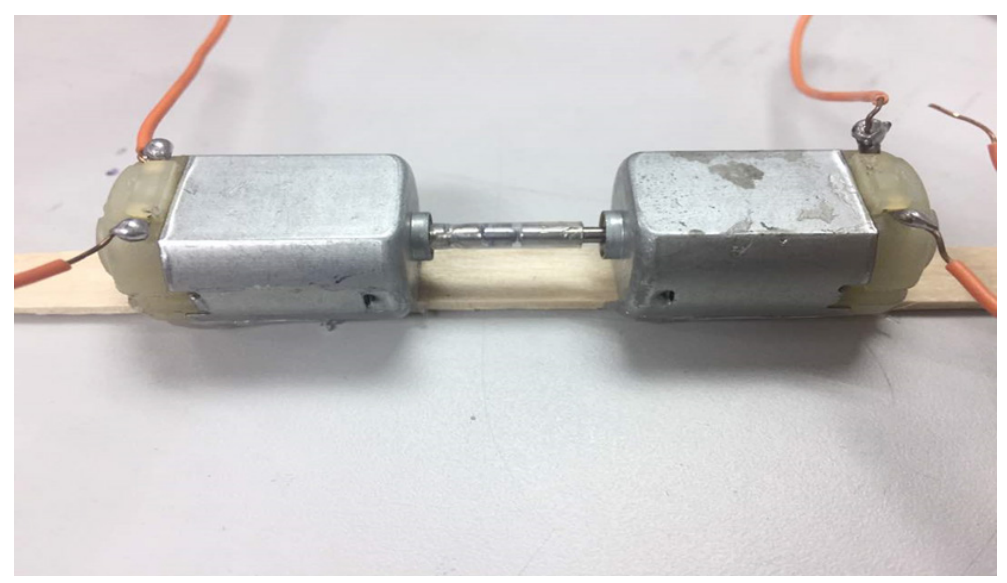

Figure 3: Conventional generator design for Case 1.

The second design is a modified one in which the stator part will be able to rotate too. Generator with dual rotation is made using three motors, two works as the input driving motor and the other as generator. Figure 4 shows the designed generator and how each connectivity parts are set. In Figure 4, the motor on the most right is the rotor driving motor and the motor on the most left is the stator driving motor. The generator that is to be measured is the one in the middle.

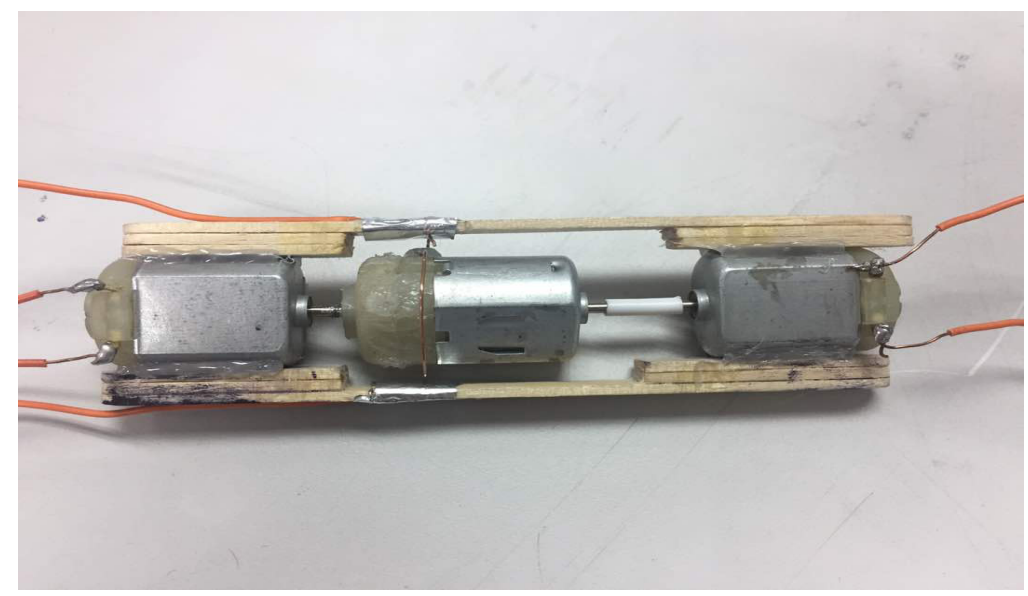

Figure 4: Designed generator that will be used for Case 2-5.

The setup made on how to measure the voltage when the stator is rotating is a challenge. This is due to the condition of wanting to measure the voltage at a point where the component is moving. To do so, the copper wire is extended from 
the stator body so that it able to act as a brush. The aluminium foil is placed side to side. The circuit activates when the extended copper wire touches the aluminium foil at the side. The close-up picture of how the aluminium foil and the extended copper wire work is shown in Figure 5.

In order to investigate the performance on the developed generator, several analyses were conducted. For reference, generator having fixed stator will be named as Generator A while the one with rotating stator will be named as Generator B. The following measurement will be recorded.

1. Output when Generator A is used.

2. Output when only the rotor driving motor rotates in the Generator B.

3. Output when only the stator driving motor rotates in the Generator B.

4. Output when both rotor and stator driving motors rotates in opposite direction in the Generator B.

5. Output when both rotor and stator driving motors rotates in the same direction in the Generator B.

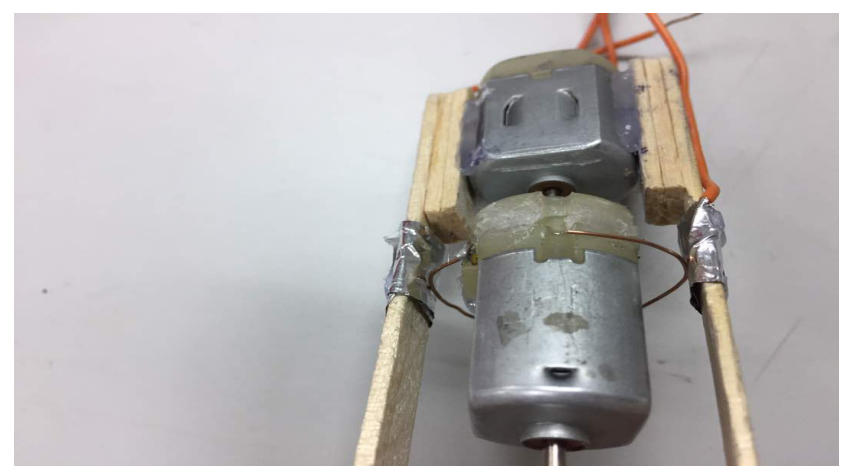

Figure 5: The aluminium foil and the extended copper wire that allows voltage flow out from the generator.

\section{RESULTS AND DISCUSSION}

This section shows and explains all the results of the experiment conducted for this project. The results taken were divided into five major parts as explained in the previous section. It will be classified as Case 1 to Case 5 for easy reference. 
Case 1: Output when Generator A is used.

Case 2: Output when only the rotor driving motor rotates in the Generator B.

Case 3: Output when only the stator driving motor rotates in the Generator B.

Case 4: Output when both rotor and stator driving motors rotates in opposite direction in the Generator B.

Case 5: Output when both rotor and stator driving motors rotates in the same direction in the Generator B.

Five clusters of input were given into each part in which the inputs are set to $1.5,2.0,2.5,3.0$ and $3.5 \mathrm{~V}$, respectively. Each output at respective inputs was recorded at least three times to get the consistent value and to avoid any errors. Next, all these results were recorded and compared using Minitab and Excel. Graphs were plotted to ease the comparison on the results.

Tables 2-6 show all the tabulated data for Case 1-5 respectively. From the measurements taken, it is seen that as the input voltage increased, the output voltage is increased too. For Case 1 and Case 2, although the condition made to the generator is the same, in which only the rotor rotates and the stator is not moving, the result is slightly lower for Case 2. This may be due to losses that occurred more in Generator B especially for the connection between the copper and the aluminium piece.

Table 2: Data collected from Case 1 - Rotor rotated in Generator A.

\begin{tabular}{cc}
\hline Input voltage of Generator A $(\mathrm{V})$ & Output voltage of Generator A $(\mathrm{V})$ \\
\hline 1.51 & 1.01 \\
1.53 & 1.02 \\
1.53 & 0.97 \\
1.98 & 1.36 \\
1.97 & 1.36 \\
1.98 & 1.37 \\
2.46 & 1.73 \\
2.47 & 1.76 \\
2.46 & 1.76 \\
2.98 & 2.21 \\
2.98 & 2.24 \\
2.96 & 2.17 \\
3.48 & 2.66 \\
3.45 & 2.65 \\
3.50 & 2.74 \\
\hline
\end{tabular}


Table 3: Data collected from Case 2 - Rotor rotated in Generator B.

\begin{tabular}{cc}
\hline Input voltage for Generator B $(\mathrm{V})$ & Output voltage for Generator B $(\mathrm{V})$ \\
\hline 1.49 & 0.56 \\
1.50 & 0.54 \\
1.52 & 0.53 \\
2.00 & 1.07 \\
2.00 & 1.09 \\
2.00 & 1.09 \\
2.50 & 1.50 \\
2.51 & 1.48 \\
2.52 & 1.48 \\
3.00 & 1.84 \\
3.00 & 1.86 \\
3.03 & 1.87 \\
3.51 & 2.16 \\
3.51 & 2.17 \\
3.51 & 2.21 \\
\hline
\end{tabular}

Table 4: Data collected from Case 3 - Stator rotated in Generator B.

\begin{tabular}{cc}
\hline Input voltage of Generator B $(\mathrm{V})$ & Output voltage of Generator B $(\mathrm{V})$ \\
\hline 1.45 & 0.55 \\
1.45 & 0.55 \\
1.46 & 0.56 \\
1.46 & 0.59 \\
1.46 & 0.59 \\
1.96 & 0.79 \\
1.96 & 0.80 \\
1.96 & 0.81 \\
1.96 & 0.82 \\
1.96 & 0.83 \\
2.50 & 0.93 \\
2.44 & 0.92 \\
2.45 & 0.93 \\
2.45 & 0.93 \\
2.46 & 0.93 \\
2.93 & 1.13 \\
2.94 & 1.13 \\
&
\end{tabular}


Table 4: (continued)

\begin{tabular}{cc}
\hline Input voltage of Generator B (V) & Output voltage of Generator B (V) \\
\hline 2.95 & 1.08 \\
2.95 & 1.09 \\
2.98 & 1.08 \\
3.53 & 1.32 \\
3.56 & 1.34 \\
3.56 & 1.36 \\
3.57 & 1.38 \\
3.57 & 1.40 \\
\hline
\end{tabular}

Table 5: Data collected from Case 4 - Both stator and rotor rotated at different direction.

\begin{tabular}{|c|c|}
\hline Input voltage of Generator B (V) & Output voltage of Generator B (V) \\
\hline 1.49 & 1.48 \\
\hline 1.49 & 1.35 \\
\hline 1.52 & 1.38 \\
\hline 1.53 & 1.38 \\
\hline 1.53 & 1.38 \\
\hline 1.98 & 2.00 \\
\hline 1.98 & 2.04 \\
\hline 1.99 & 2.03 \\
\hline 1.99 & 2.04 \\
\hline 2.02 & 2.03 \\
\hline 2.48 & 2.64 \\
\hline 2.48 & 2.60 \\
\hline 2.50 & 2.60 \\
\hline 2.51 & 2.64 \\
\hline 2.52 & 2.66 \\
\hline 2.99 & 3.17 \\
\hline 3.0 & 3.18 \\
\hline 3.01 & 3.15 \\
\hline 3.02 & 3.14 \\
\hline 3.02 & 3.16 \\
\hline 3.45 & 3.49 \\
\hline 3.44 & 3.52 \\
\hline 3.50 & 3.46 \\
\hline 3.51 & 3.50 \\
\hline 3.50 & 3.49 \\
\hline
\end{tabular}


Table 6: Data collected from Case 5 - Both stator and rotor rotated at same direction.

\begin{tabular}{cc}
\hline Input voltage of Generator B (V) & Output voltage of Generator B (V) \\
\hline 1.47 & 0.0235 \\
2.02 & 0.0185 \\
2.55 & 0.0234 \\
3.09 & 0.00351 \\
3.5 & 0.0124 \\
\hline
\end{tabular}

Figure 6 demonstrates the graphs plotted based on all the recorded data. From this figure, there are few things that can be observed based on the experiment analyses that have been conducted.

1. As mentioned earlier, the dashed line with square shaped points which represent measurements for Case 2 is lower than the solid line with circle shaped which represent Case 1 measurement. The gradient of the line is almost the same. This is due to the loss made in the connection between the copper and aluminum piece in the Generator B.

2. The dashed line with diamond shaped points which represent Case 3 (only stator is rotating) is lower than the solid line circle shaped and the dashed line square shaped (only rotor is rotating). The gradient of the line has also decreased. This result is due to the loss made in the connection between the copper and aluminum piece in the Generator B and also due to the effect of friction. From this also one can observed that in comparison of ability to rotate, the rotor part will give higher output as compared to the stator part.

3. The dashed dot line with triangular shaped points which represent the outcome of Case 4 is higher than all other cases and also has a greater gradient as compared to others. From this analysis, it is observed that when both rotor and stator rotate, it will increase the flux cut thus increase the output voltage. Even tough, the result obtained from these experiments is not up to the theoretical expectation (the voltage should be doubled) due to losses, the outcome is still acceptable as the value is higher as compared to standard configuration which run for Case 1 and Case 2.

4. On the last note, the dashed line with triangular shaped points which represent the outcome of Case 5 is almost zero for all measurements. This happened due to no flux cut in the Generator B as both the stator and rotor are rotating on the same direction. The very minimum value is due to relative different of speed of rotor and stator that is moving. 


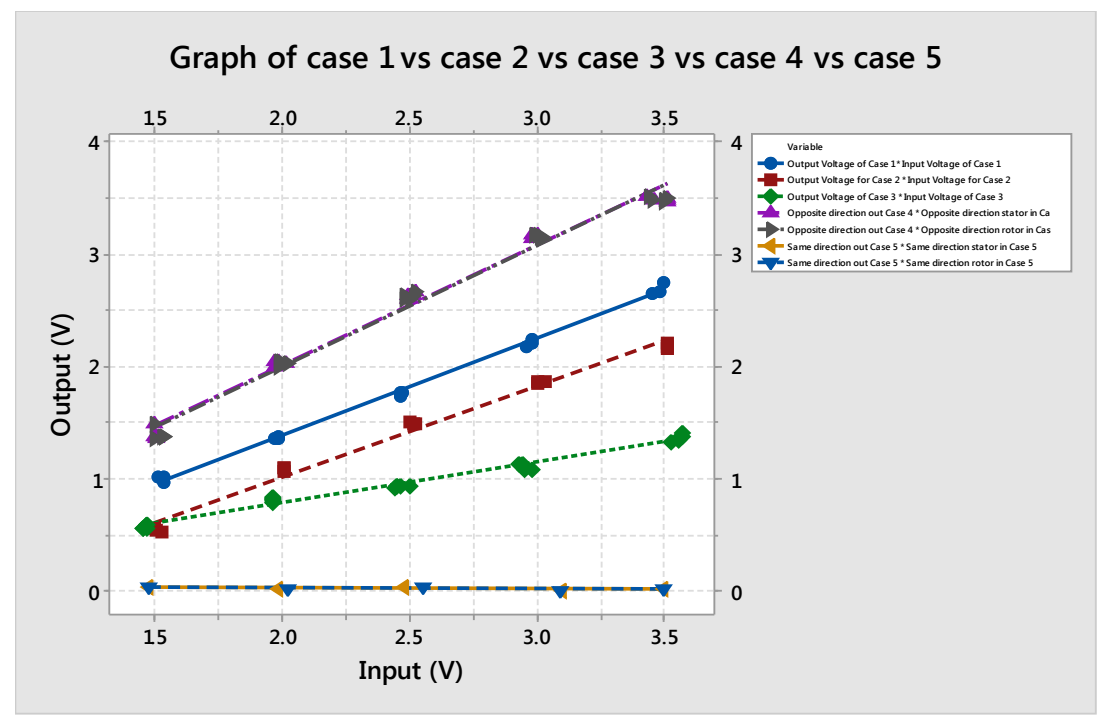

Figure 6: Comparison graph of all recorded data.

\section{CONCLUSION}

Overall, the aim of this project that is to develop a mini DC Generator in which the rotor and stator is able to counter rotate is achieved. The objectives of this project have been achieved such that

1. The DC generator by having the stator that can rotate was developed.

2. The effect of rotating stator in electrical machine system was observed and data were recorded.

3. Comparison was made to all the measurements taken when different set of rotation was used.

The designed generator where both rotor and stator rotate in opposite direction produces output more than the conventional generator, although it is not up to double the value. In this analysis, only maximum of $3.5 \mathrm{~V}$ power supply was used in all measurements. This was done so because of the breakage of the extended copper wire in the generator due to friction and heat if the higher supply is given. 
It is undeniable that there are losses in many parts of the designed generator. The results obtained is not up to the theoretical value but it is more than the individually recorded output from only rotor rotating generator and only stator rotating generator. In conclusion, with due respect to the ability of stator to also rotate in the DC generator system, the possibility of more output will be produced and hence more power will be generated can be considered for further improvement in power generation application.

\section{ACKNOWLEDGEMENTS}

This project is partially supported by the FRGS Grant 304/ PELECT/6071291. The authors would like to thank Universiti Sains Malaysia for providing the facility in conducting the project. Acknowledgement also goes to the Ministry of Education, Malaysia for the awarded grant to support this project.

\section{REFERENCES}

1. Guru, B. S. \& Hiziroglu, H. R. (2000). Electric machinery and transformers. 3rd Ed. New York: Oxford University Press.

2. Wildi, T. (2006). Electrical machines, drives and power systems. 6th Ed. New Jersey: Pearson Prentice Hall.

3. Chapman, S. J. (2005). Electrical machinery fundamentals. 4th Ed. New York: McGraw Hill.

4. Pal, D. (2016). An introduction to DC generator using MATLAB/Simulink. Imp. J. Interdiscip. Res., 2(4), 935-938.

5. Kothari, D. P. \& Nagrath, I. J. (2010). Electric machines. 4th Ed. New Delhi: McGraw Hill.

6. Cress, K. (2014). Changing an induction motor's power supply frequency between 50 and $60 \mathrm{~Hz}$. Retrieved from http://www.engineering.com/ ElectronicsDesign/ElectronicsDesignArticles/ArticleID/8154/Changingan-Induction-Motors-Power-Supply-Frequency-Between-50-and-60Hz. aspx on 28 May 2017.

7. Circuit Globe (2017). Applications of DC machines. Retrieved from http:// circuitglobe.com/applications-of-dc-machines.html on 5 May 2017.

8. Miller, K. \& Ata, K. (2006). Mechanism for rotating the rotor/s, stator/s and electric power generator/s. Publication no. US 2006/0125243 A1, United States Patent and Trademark Office.

9. Amutham, V. K. (2010). Wheel motor with rotating stator. Publication no. US 2010/0301712 A1, United States Patent and Trademark Office. 
10. Bogdanovic, Z. (2016). Electric generator with rotating stator and application. Publication no. WO 2016/114680 A1, World Intellectual Property Organization.

11. Degirmenci, A. (2016). Rotating stator motor. Publication no. WO 2016/137418 A1, World Intellectual Property Organization. 